\title{
Serpiginous choroiditis: a complex pharmacotherapeutic approach
}

\author{
Amitrajit A. Pal*, Abhijeet D. Joshi
}

Department of Pharmacology, Grant Government Medical College \& Sir JJ Group of Hospitals, Mumbai, Maharashtra, India

Received: 28 June 2020

Accepted: 14 July 2020

*Correspondence:

Dr. Amitrajit A. Pal,

Email: amitrajitmodakpal@gmail.com

Copyright: (c) the author(s), publisher and licensee Medip Academy. This is an open-access article distributed under the terms of the Creative Commons Attribution Non-Commercial License, which permits unrestricted non-commercial use, distribution, and reproduction in any medium, provided the original work is properly cited.

\begin{abstract}
Serpiginous choroiditis is a rare recurrent eye disorder which is characterized by formation of irregularly shaped (serpiginous) lesions involving two layers of the eye surface (the retinal pigment epithelium and the choriocapillaris). It is a rare clinical entity which causes less than $5 \%$ of posterior uveitis cases $(3.9 / 1,00,000$ person-years). Diagnosing this rare disorder is a challenge in itself followed by its complex pharmacotherapeutic approach which is seen in the following case report. It will aid in bringing to light the various challenges faced in treatment to open a window for early diagnosis and better treatment regimens while keeping in mind the constant motivation and relaxed mind a patient needs to fight such a rare disease.
\end{abstract}

Keywords: Serpiginous, Choroiditis, Lesions, Uveitis, Rare

\section{INTRODUCTION}

Serpiginous choroiditis is a rare recurrent eye disorder which is characterized by irregularly shaped (serpiginous) lesions involving two layers of the eye surface (the retinal pigment epithelium and the choriocapillaris). No symptoms are apparent until and unless a specific area of the retina (macula) is damaged. ${ }^{1}$ A sudden, painless decrease in vision in one or both eyes may be the first sign of serpiginous choroiditis. The exact cause of it is not known. Symptoms develop due to lesions that damage the part of the retina that absorbs short wavelengths of light (macular region). Vision loss may also occur if a membrane composed of fibers and blood vessels (subretinal neovascular membrane) develops and then moves into the macular region. It usually affects males more often than females. Symptoms usually appear during the early to middle adult years. ${ }^{2}$

\section{CASE REPORT}

A 15 year old boy presented to Ophthalmology Outpatient Department with chief complaints of seeing black spots in his left ocular field of vision along with pain for few days, with no history of type 2 diabetes mellitus and hypertension. After fundus examination a clinical diagnosis of serpiginous choroiditis was made and to confirm the activity of the lesions a fundus fluorescein angiogram (FFA) was done which showed that there was significant activity of lesions near the fovea which is the area for best vision. The patient was admitted and started on intravenous methyl prednisolone 1 gram for three days after a series of rapid investigations and a chest X-ray. A decision was made to rule out sarcoidosis and tuberculosis (TB) to prevent flaring up of underlying infection due to prednisolone. To rule out sarcoidosis, angiotensin converting enzyme was evaluated and for tuberculosis, mantoux test, chest X-ray, quantiferol gold TB test was done out of which mantoux test and quantiferol gold TB test was positive for the patient. To evaluate further the chest x-ray had tuberculous foci, due to which the patient was started on Anti-tubercular drug therapy for one year with rifampicin, ethambutol, pyrazinamide, and ciprofloxacin. The patient was also then put on oral prednisolone starting at a dose of $1 \mathrm{mg} / \mathrm{kg}$ body weight. During the 
course of one year the dosage was gradually tapered on a weekly basis. After few months due to raised liver enzymes (alanine transaminase - $384 \mathrm{IU} / \mathrm{ml}$ ) a decision was made to stop rifampicin and the patient was started on Isoniazid. Over the course of time the patient developed severe anorexia and right hypochondriacal pain due to liver enlargement. The course was completed in one year.

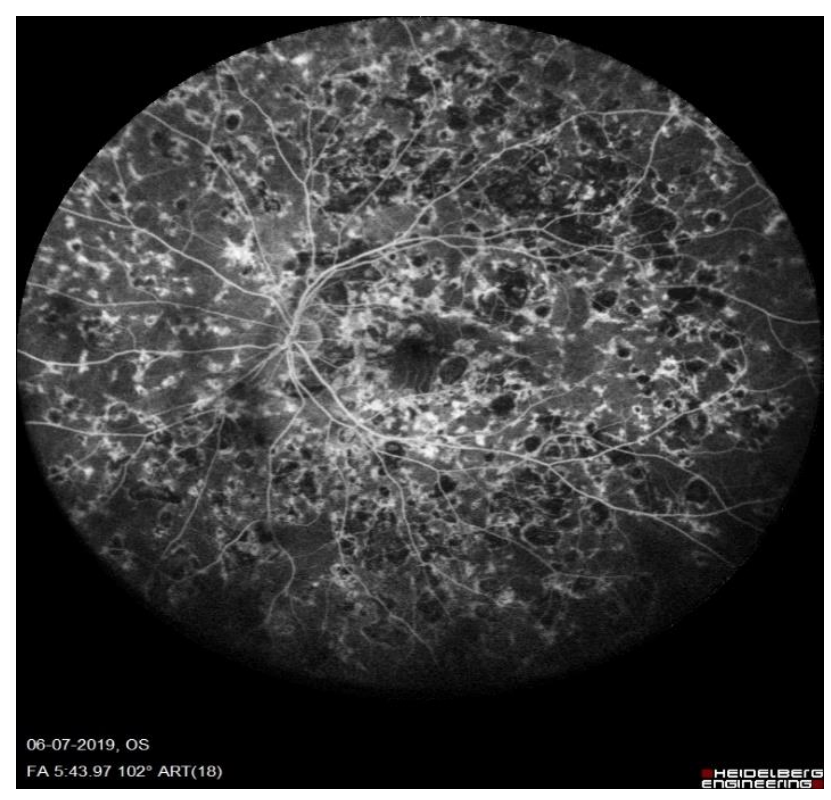

Figure 1: Fundus fluorescein angiogram of the left eye of the patient at the time of diagnosis.

Over the course of five years there were several relapses and each relapse was significantly associated with an increased amount of stress as complained by the patient that he experienced pain in his left eye along with multiple black spots in his field of vision. Oral prednisolone was started after FFA which was gradually tapered on a weekly basis. Another important case finding was that after restarting prednisolone therapy, the patient gradually became calm with reduced anxiety and apprehension as reported by his family. Over the past few years he needed constant motivation to take the medication.

Two more years later the patient reported of seeing black spots in his right eye along with similar symptoms, and after proper examination and FFA, serpiginous choroiditis was diagnosed in the right eye as well, but since the activity of the lesions were less as compared to the left eye, oral prednisolone was started on tapering dose and a decision was made to put the patient on Azathioprine as a steroid sparing agent because the patient had been on prednisolone for the last seven years and he had many complications and side effects related to it - opportunistic infections, rashes in the face and trunk, increase in intraocular pressure, etc. After a series of rapid investigations it was decided to put the patient on azathioprine $30 \mathrm{mg}$ thrice daily and the blood profile was kept on sharp check from time to time. Patient compliance to azathioprine was good for the first two weeks after which the patient's blood profile revealed moderate thrombocytopenia and elevated liver enzymes. The medication was given for six months and due to the falling levels of platelet levels and poor patient compliance it was decided to stop azathioprine and again the patient was reinstated on prednisolone. After that prednisolone was tapered on a regular basis and treatment regimen was changed from time to time like giving prednisolone on alternate days to prevent relapses. At present the patient is on $10 \mathrm{mg} / \mathrm{kg}$ body weight after a recent relapse.

\section{DISCUSSION}

Medical treatment of choroiditis is often limited and controversial causing doctors to turn to complex therapeutic approaches and drug combinations in order to provide safe and effective therapies for this rare ocular disease. $^{3}$ Serpiginous Choroiditis is usually underdiagnosed by general ophthalmologists. The reported prevalence of it also varies geographically. A referralbased epidemiologic study found that it represented $18.9 \%$ of posterior uveitis cases in India. In this series, the autoimmune condition is reported as "peri-papillary geographic helicoid choroiditis." In contrast, the reported prevalence of it in areas where tuberculosis is not endemic generally varies from $1.6 \%$ to $5.3 \%$ of posterior uveitis. The higher prevalence of serpiginous choroiditis in India may reflect the presence of tuberculous choroiditis, which can mimic it. Although initial reports described serpiginous choroiditis in Caucasians, the disease has been observed in Asian, African American, Middle Eastern, Asian Indian, and Spanish patients. ${ }^{4}$ In a study by Rathinam in Southern India, out of 5500 cases studied, only 1 patient was diagnosed with serpiginous choroiditis. 5

About the disease and its treatment, the most complex challenging and complex part its treatment as the occurrence of this disease in early adolescent age group hampers the patient's growth and development, both mentally and physically, in addition to which intake of prednisolone leads to stunted growth. Black spots in the field of vision increase the stress levels which in turn lead to flaring up of the lesions and thus more stress, which is in a way an influential factor in the relapse of the disease. The drugs used in the treatment causes a lot of ocular side effects which can be problematic and create complications in the patients already suffering from ocular conditions like, ethambutol causing optic neuritis, prednisolone causing increase in intraocular pressure leading to glaucoma and on a later stage, posterior sub-capsular cataract, azathioprine causing bone marrow suppression. ${ }^{6,7}$ Moreover the usage of prednisolone in patient with tuberculosis is a challenge in itself when it can cause any latent infection to flare up. So, when they are given with anti-tubercular therapy, a lot of complications arise, hepatotoxicity being an important side effect. In a disease with no definitive cause, the 
curative treatment protocol gets jeopardised when the only mode of treatment is palliative.

\section{CONCLUSION}

So overall, if we see the treatment of serpiginous choroiditis, we will understand that there is no definitive treatment protocol as such till now and the drugs which are used have harmful impact on the already existing conditions like tuberculosis or growth of the victim and also on eyes of the patient. So, choosing a correct treatment may not be comfortable or suitable for the patient, physically or mentally with taking compliance into account. Looking at the complexity of the treatment, one has to undergo a battery of drugs while compromising other factors.

\section{Funding: No funding sources}

Conflict of interest: None declared

Ethical approval: Not required

\section{REFERENCES}

1. Kanski's Clinical Ophthalmology. Kanski JJ, ed. Clinical Opthalmology, 2nd Edition. ButterworthHeineman, 1990: 171-172.
2. Laatikainen L, Erkkilä H. A follow-up study on serpiginous choroiditis. Opthalmologys. 1981;59(5)707-18.

3. Denniston AK, Barry RJ. Controversies in the Pharmacological Treatment of Uveitis. Curr Pharm Des. 2015 ;21(32):4682-7.

4. Biswas J, Narain S, Das D, Ganesh SK. Pattern of uveitis in a referral uveitis clinic in India. Int Ophthalmol. 1996;20(4):223-8.

5. Rathinam SR, Krishnadas R, Ramakrishnan R, Thulasiraj RD, et al. Population-based prevalence of uveitis in Southern India. $\mathrm{Br} \mathrm{J}$ Ophthalmol. 2011;95(4):413-7.

6. Citron KM, Thomas GO. Ocular toxicity from ethambutol. Thorax. 1986;41:737-9.

7. Hadda V, Pandey B D, Gupta R, Goel A. Azathioprine induced pancytopenia: A serious complication. J Postgrad Med. 2009;55:139-40.

Cite this article as: Pal AA, Joshi AD. Serpiginous choroiditis: a complex pharmacotherapeutic approach. Int J Basic Clin Pharmacol 2020;9:128991. 